\title{
Influence of the trajectory of air masses on the in situ measurements of aerosol properties in Valencia
}

\author{
A. R. Esteve ${ }^{1}$, V. Estellés ${ }^{1,2}$, S. Segura ${ }^{1}$, M. P. Utrillas ${ }^{1}$ and J. A. Martínez-Lozano ${ }^{1}$ \\ ${ }^{1}$ Department of Earth Physics and Thermodynamics, Universitat de València, Dr. Moliner 50, 46100 Burjassot, Valencia \\ ${ }^{2}$ Department of Fundamental and Experimental Physics, Electronics and Systems, Universidad de La Laguna, Astrofísico \\ Francisco Sánchez s/n, 38207 La Laguna, Tenerife
}

Received: 3-XI-2011 - Accepted: 18-V-2012 - Translated version

Correspondence to: Anna.Esteve@uv.es

\begin{abstract}
We analyzed the influence of the trajectory of air masses on the in situ measurements of aerosol properties (scattering and backscattering coefficients and scattering Angström exponent) in Valencia (Spain) for the March 2006 to December 2009 period. The scattering $\left(\sigma_{s p}\right)$ and backscattering $\left(\sigma_{b s p}\right)$ coefficients were measured with a TSI 3563 integrating nephelometer. From the $\sigma_{s p}$ and $\sigma_{b s p}$ measurements, it is also possible to calculate the scattering Angström exponent $\left(\alpha_{s}\right)$. By classifying the source regions of air masses by sectors, it has been possible to establish the dependence of aerosol properties on the type of dominant air mass, proving that in situ measurements of aerosol properties are parameters that are sensitive to the type of air mass. The highest values of scattering and backscattering coefficients are obtained under the influence of masses from North Africa and the European continent, while the lowest are obtained for Arctic-type air masses. The scattering Angström exponent presents its highest values under the influence of European-type masses, while the lowest values are obtained for Arctic and Polar type masses.
\end{abstract}

Key words: aerosol properties, air masses, in situ measurements

\section{Introduction}

An air mass is usually defined as a volume of air whose physical properties (mainly temperature and humidity) remain relatively constant across surfaces of hundreds to thousands of square kilometers (Barry and Chorley, 1998). Air masses acquire their characteristics when interacting with the surfaces above which they are located (source regions), where they must remain stationary for a certain time. The source regions should also be sufficiently large and homogeneous to be able to print their characteristics on the air mass.

Although the traditional definition of air mass does not take into account the properties of the particles suspended in it, it is reasonable to assume that the continuous interaction between the surface of the source region and the air mass will also determine the nature and concentration of its aerosols. This is especially true when considering that the average life of particles in the troposphere is 5 to 10 days, thus an air mass that remains for several days over the same region will have much of its previous aerosol load replaced by that of the new corresponding source region. Actually, it is likely that air masses are not pure masses, either because of having undergone a homogeneous or heterogeneous mixture with masses of other features, or because they have spent some time traveling over other regions.

A way to study the relationship between the type of air masses and aerosols is to calculate the historical or back trajectory followed by the air parcel that is over a region at a given moment. Some studies have used back trajectories to analyze the origin of air masses prevailing in a given time, and thus understand the origin of the carried particles (Grousset et al., 2003; Niemi et al., 2004; Estellés et al., 2007a; Toledano et al., 2009). In a more limited number of cases, back trajectories have been classified in order to understand the role of transportation in local aerosol climatology (Birmili et al., 2001; Gerasopoulos et al., 2003; Slater and Dibb, 2004). Other studies have used cluster analysis as a method of classifying air masses (Dorling et al., 1992; Mattis et al., 2000; He et al., 2003; Rozwadowska et al., 2010). 
In this paper, we have analyzed the influence of the trajectory of air masses on the in situ measurements of atmospheric aerosol properties made in Valencia (Spain) with a TSI 3563 integrating nephelometer for the March 2006 to December 2009 period. By classifying the source regions of air masses into sectors, and with the help of a simple model (Estellés et al., 2007a) that quantifies the relative influence of each sector on the final character of air masses reaching the measuring station, it is possible to classify and understand the dependence of aerosol properties on the dominant air mass type. The climatology of some aerosol properties measured in the atmospheric column and in situ in this town have been presented in previous studies (Estellés et al., 2007b; Esteve et al., 2012).

The knowledge of the physical and chemical properties of atmospheric aerosols is essential to understand their effect on the Earth's climate, both regionally and globally (Charlson and Heintzenberg, 1995). The Mediterranean is one of the most interesting regions of the planet in this sense, since its atmosphere is subject to different influences, both from local and remote sources. The specific region of this study, in the western Mediterranean extreme, is subject to the influence of particles from regions as diverse as the desert regions of North Africa, the continental shelf of Western Europe and the Atlantic Ocean. The characteristics of the aerosols from each of these regions are very different and will determine the properties of the atmospheric aerosols measured over the region. The combination of the atmospheric dynamics and the geographical location and the topography of the study area favors the development of mesoscale circulations (sea and mountain breezes), especially during the spring and summer months, meaning the aerosol transportation mainly takes place inland from the coast. The physical processes that determine air quality in this area have been previously documented (Millán et al., 1996, 1997, 2000).

Although the classification of air masses done by Estellés et al. (2007a) has only been applied to this specific Mediterranean region, the results can be considered valid for the entire Mediterranean coast of the Iberian Peninsula. Also, considering that the properties of aerosols at a certain time in a region are the result of contributions from local sources and distant sources, these results may also be valid for southwest Europe. Although the contribution of local sources largely depends on the specific location of the study (for example, proximity to urban sources), the contribution of distant sources will be more spatially homogeneous and will be determined by the air mass, being therefore representative of a broader region.

\section{Methodologies and materials}

\subsection{Measurement season and period}

The measurements of atmospheric aerosol properties were made with a TSI 3563 integrating nephelometer during the March 2006 to December 2009 period, at the measuring station installed on the terrace of the Faculty of Physics at the Burjassot Campus of the Universitat de València (39.507 latitude, longitude $-0.420^{\circ}$, approximately 60 meters above sea level). Due to technical problems, measurements were interrupted between February 2007 and October 2008.

Burjassot is a city of 38,400 inhabitants located northwest of the metropolitan area of Valencia, with a total population of 1,832,000 inhabitants. Given its proximity to the main population center ( $5 \mathrm{~km}$ to the southeast), the station is under the direct influence of the urban and industrial pollution typical of a metropolitan area. Its proximity to the western coast of the Mediterranean Sea (10 km to the east) also determines the type of aerosols and their dynamics in this region.

\subsection{Instruments and measurements}

The aerosol scattering $\left(\sigma_{s p}\right)$ and backscattering $\left(\sigma_{b s p}\right)$ coefficients were measured at three wavelengths $(\lambda=450$, $550,700 \mathrm{~nm}$ ) with a TSI 3563 integrating nephelometer (Anderson et al., 1996; Heintzenberg and Charlson, 1996). The measurements were performed at ambient relative humidity at $15 \mathrm{~m}$ above the ground. The averaging time of the measurements was 1 minute, and the zero signal of clean air was measured every hour for 5 minutes. The flow rate was set at $301 \mathrm{~min}^{-1}$. The nephelometer was calibrated at least twice a year (every 4 to 6 months) using $\mathrm{CO}_{2}$ and air as high and low span gases, respectively. The uncertainty in the nephelometer measurements considering the angular truncation errors, the non-Lambertian nature of the light source, the wavelength non-idealities and the calibration errors is about 7\% (Anderson et al., 1996; Anderson and Ogren, 1998).

The nephelometer measurements were adjusted to standard pressure $(1013 \mathrm{hPa})$ and temperature $\left(0^{\circ} \mathrm{C}\right)$ conditions. Due to the design of the instrument, the measurements of the scattering and backscattering coefficients do not cover the entire angular range $\left(0-180^{\circ}\right)$, so that a truncation correction for particles with "no size cut" was applied to them (Anderson and Ogren, 1998). Due to the lamp heating, the relative humidity inside the nephelometer during the study period ranged from 30 to $60 \%$ with a mean value of $45 \pm 10 \%$, and we can therefore consider that the measurements presented in this paper correspond to dry particles (Targino et al., 2005).

The measurements of the scattering coefficients at wavelengths of $450 \mathrm{~nm}\left(\sigma_{s p}^{450 \mathrm{~nm}}\right)$ and $700 \mathrm{~nm}\left(\sigma_{s p}^{700 \mathrm{~nm}}\right)$ can be used to calculate the scattering Ångström exponent $\left(\alpha_{s}\right)$ with the expression:

$\alpha_{s}=-\frac{\ln \left(\frac{\sigma_{s p}^{450 \mathrm{~nm}}}{\sigma_{s p}^{700 \mathrm{~nm}}}\right)}{\ln \left(\frac{450}{700}\right)}$

The scattering and backscattering coefficients are indicators of the amount of aerosol in the atmosphere, while the scattering Ångström exponent reflects the nature of aerosols. Aerosol properties that depend on the amount of particles present are often called extensive properties, whereas those 

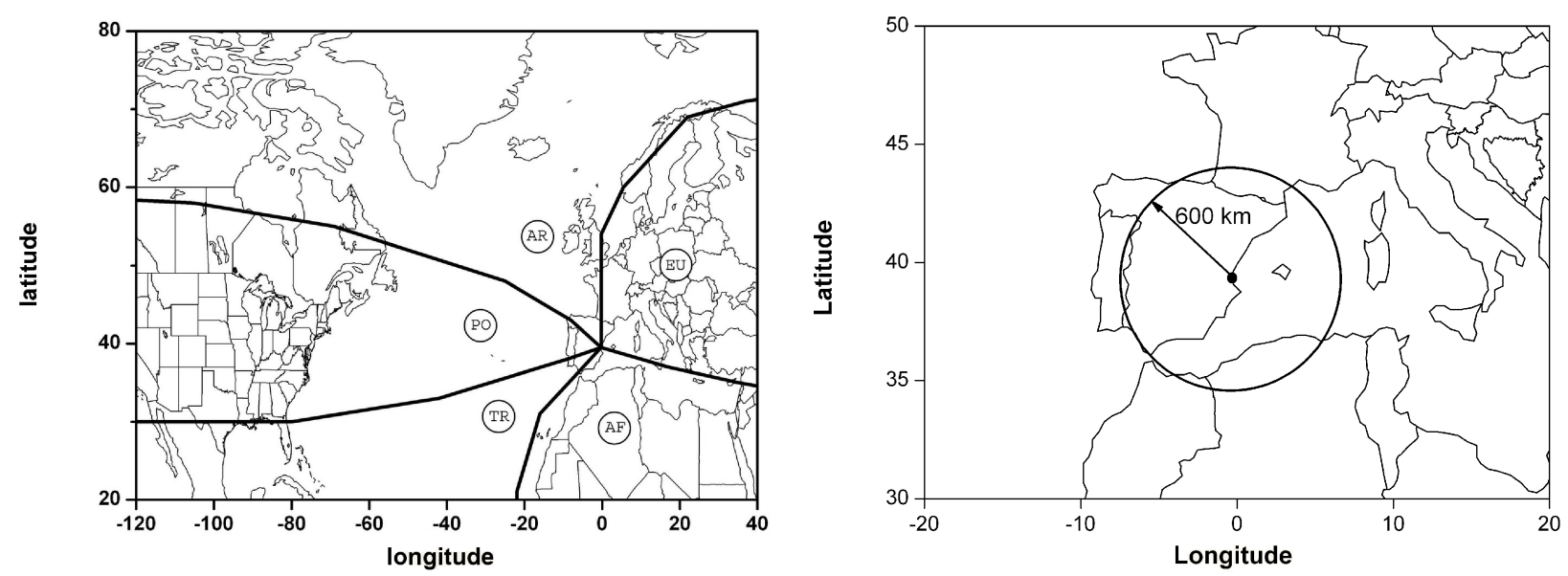

Figure 1. Main areas for backscattering trajectory classification: European (EU), African (AF), Tropical (TR), Polar (PO), Arctic (AR) and Regional (O).

related to the nature of the aerosol are called intensive properties (Ogren, 1995).

This study only shows the results obtained for the $550 \mathrm{~nm}$ wavelength, as the scattering and backscattering coefficients on the other wavelengths behave quite similarly. This $550 \mathrm{~nm}$ wavelength is especially important because the sun emits its maximum intensity at around $500 \mathrm{~nm}$, so it is used for atmospheric correction of satellite images as well as for radiative transfer models.

\subsection{Air masses classification}

The HYSPLIT model (HYbrid Single-Particle Lagrangian Integrated Trajectory), developed by NOAA (National Oceanic and Atmospheric Administration) (Draxler and Rolph, 2003), offers the possibility to obtain the trajectory of the air parcel (and some key meteorological parameters) quantitatively in text format files. Estellés et al. (2007a) designed a simple classification model for describing the back trajectories using basic indices, thereby giving the air mass a primary or secondary feature. The applied vertical transportation model is that directly obtained from the vertical speed fields of the meteorological file. The flying time is limited to 5 days (120 hours), reaching the study area at 12:00 GMT. There are five areas selected by Estellés et al. (2007a) to classify the origin of the different back trajectories: European (EU), African (AF), Tropical (TR), Polar (PO) and Arctic (AR). Complementarily, they also define a regional class $(\mathrm{O})$ (Figure 1). These sectors were defined considering both definitions based on temperature and surface type of the source region of air masses and other aspects related to aerosol physics.

In this simple classification model, some percentage indices $\zeta_{i}$ are defined, which describe the nature of an air mass in terms of the basic classes, and which are obtained by dividing the number of hours that the air mass needs to move through a particular sector $i\left(t_{i}\right)$, and the total travelling time

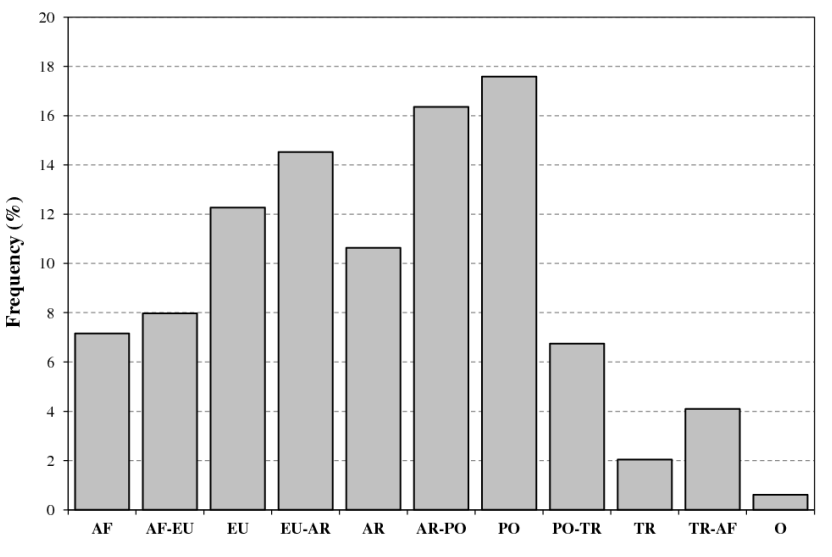

Figure 2. Incidence of each type of air mass in Valencia in the March 2006 to December 2009 period. AF: African, EU: European, AR: Arctic; PO: Polar, TR: Tropical, O: Regional.

(in our case, $\mathrm{T}=120 \mathrm{~h}$ ). Both values are weighted by two factors that take into account the average lifetime of aerosols and the height of the air parcel from the ground, which in our case have been set at $120 \mathrm{~h}$ and 2,000 m. To assign a definite character to each set of back trajectories, in practice we say that an air mass is pure $i$ class if the index $\zeta_{i}$ has a value of more than $80 \%$. Otherwise, the mass will be considered as mixed, and its composition will include all classes whose indices are larger than $20 \%$. Henceforth, we will only work with pure masses, or mixed masses consisting of only two pure mass types.

To improve the temporal consistency between the back trajectories used in the classification of air masses and the measurements of aerosol properties, hourly average values have been used, which were calculated from data recorded every minute between 12:00 GMT and 13:00 GMT, in a manner that minimizes the effect of daily variability due to local sources. 

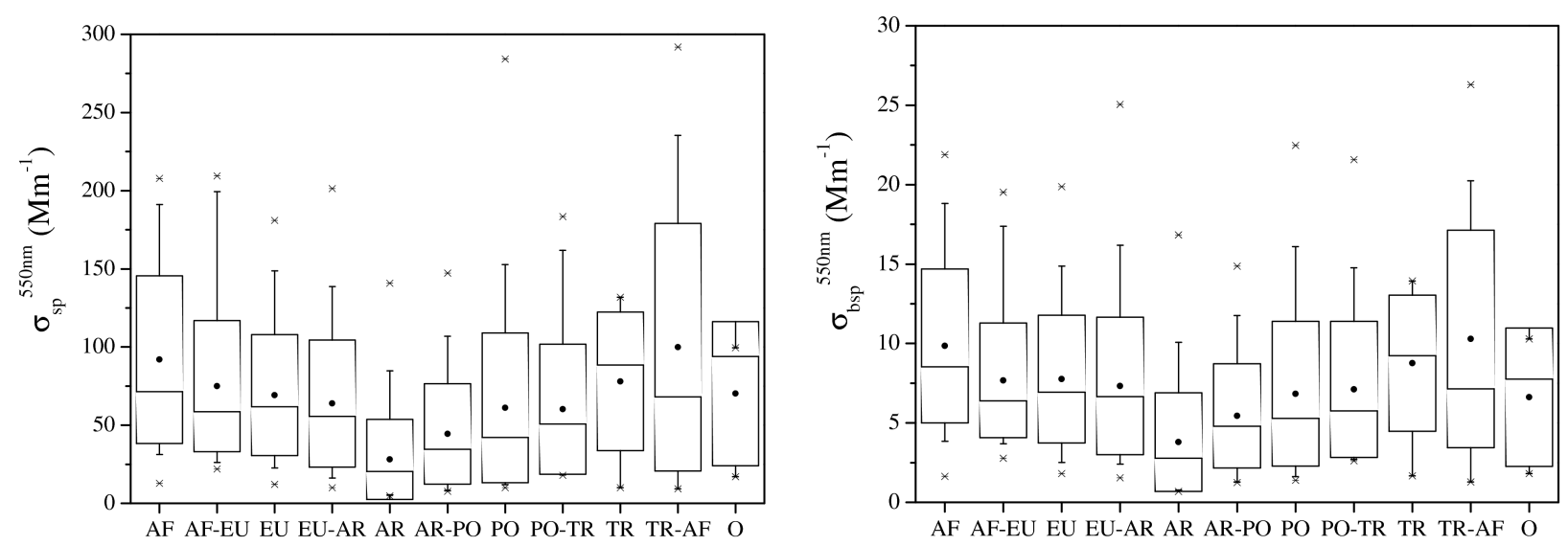

Figure 3. Dependence of the scattering $\left(\sigma_{s p}\right)$ and backscattering $\left(\sigma_{b s p}\right)$ coefficients at $550 \mathrm{~nm}$ on the air mass. AF: African, EU: European, AR: Arctic, PO: Polar, TR: Tropical, O: Regional.

\section{Results}

The incidence of each type of air mass, pure and mixed of two classes, in Valencia during the study period is shown in Figure 2. It can be observed that the most common air masses are PO (17.6\%), AR-PO (16.4\%) and EU-AR (14.5\%) types, while TR-type and O-type masses are the least frequent ( $2 \%$ and $0.6 \%$ respectively). These results agree in part with those obtained by Estellés et al. (2007a) for the same region, with AR-PO and AF types being the most frequent air masses and TR-types being the least frequent. In our case, the AF-type air masses are not as frequent, as the period considered in this study contains more winter months than summer months, and AF-type air masses show a frequency maximum in the summer months and a minimum in the winter months (Estellés, 2006).

\subsection{Scattering and backscattering coefficients}

Scattering and backscattering coefficients are indicators of the attenuation of solar radiation due solely to aerosol dispersion on an angular range of $0-180^{\circ}$ and $90-180^{\circ}$, respectively.

Figure 3 shows the classification of the scattering $\left(\sigma_{s p}\right)$ and backscattering $\left(\sigma_{b s p}\right)$ coefficients at $550 \mathrm{~nm}$ with the air mass in a box-plot. In these box-plots, the mean is indicated by a dot. The upper and lower limits of the box indicate the mean plus and minus the standard deviation. The vertical bars of the box represent the $P_{5}$ and $P_{95}$ percentiles. The dividing line of the box indicates the median. The crosses refer to the $P_{1}$ and $P_{99}$ percentiles, which in most cases are indistinguishable from the minimum and maximum, represented as a horizontal segment.

Although the scattering $\left(\sigma_{s p}\right)$ and backscattering $\left(\sigma_{b s p}\right)$ coefficients at $550 \mathrm{~nm}$ were measured in situ at ground level, these parameters are observed to be sensitive to the type of predominant air mass. Days that show higher $\sigma_{s p}$ and $\sigma_{b s p}$ values are under the influence of mixed and pure masses of

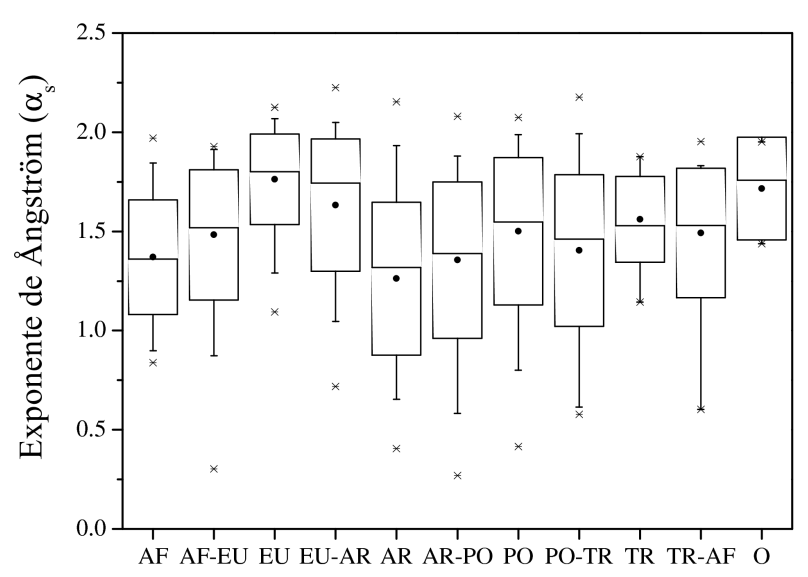

Figure 4. Dependence of the scattering Ångström exponent $\left(\alpha_{s}\right)$ on the air mass. AF: African, EU: European, AR: Arctic, PO: Polar, TR: Tropical, O: Regional.

AF and EU types. TR-type masses also present high values of $\sigma_{s p}$ and $\sigma_{b s p}$, probably due to the presence of traces of mineral dust from a desert source added to the effect of relatively high temperatures and humidity that favor hygroscopic growth of sea salt and other aerosols resulting from gasparticle conversion. O-type masses show high $\sigma_{s p}$ and $\sigma_{b s p}$ values because they are stagnant in the study area due to low pressure gradient in anticyclone situations, facilitating the accumulation of various anthropogenic pollutants which, in the Mediterranean basin, are added to possible dust of peninsular or African origin. The minimum of $\sigma_{s p}$ and $\sigma_{b s p}$ are found in AR-type masses, which are the cleanest masses. These results agree with those obtained by Estellés et al. (2007a) for aerosol optical thickness in the same region, with maximum values for air masses of pure AF type and mixed with masses of EU and TR types, and minimum values for those of AR and PO types. 
Table 1. Average and standard deviation of the scattering and backscattering coefficients at $550 \mathrm{~nm}$ and of the scattering Ångström exponent according to the dominant air mass (N: number of days; air mass type, AF: African, EU: European, AR: Arctic, PO: Polar, TR: Tropical, O: Regional).

\begin{tabular}{lcccc}
\hline & $\begin{array}{c}\sigma_{s p}^{550 \mathrm{~nm}} \\
\left(\mathrm{Mm}^{-1}\right)\end{array}$ & $\begin{array}{c}\sigma_{b s p}^{550 \mathrm{~nm}} \\
\left(\mathrm{Mm}^{-1}\right)\end{array}$ & $\alpha_{s}$ & $\mathrm{~N}$ \\
\hline $\mathrm{AF}$ & $90 \pm 50$ & $10 \pm 5$ & $1.4 \pm 0.3$ & 35 \\
$\mathrm{AF}-\mathrm{EU}$ & $80 \pm 40$ & $8 \pm 4$ & $1.5 \pm 0.3$ & 39 \\
EU & $70 \pm 40$ & $8 \pm 4$ & $1.8 \pm 0.2$ & 60 \\
EU AR & $60 \pm 40$ & $7 \pm 4$ & $1.6 \pm 0.3$ & 71 \\
AR & $30 \pm 30$ & $4 \pm 3$ & $1.3 \pm 0.4$ & 52 \\
AR PO & $40 \pm 30$ & $5 \pm 3$ & $1.4 \pm 0.4$ & 80 \\
PO & $60 \pm 50$ & $7 \pm 5$ & $1.5 \pm 0.4$ & 86 \\
PO TR & $60 \pm 40$ & $7 \pm 4$ & $1.4 \pm 0.4$ & 33 \\
TR & $80 \pm 40$ & $9 \pm 4$ & $1.6 \pm 0.2$ & 10 \\
TR AF & $100 \pm 80$ & $10 \pm 7$ & $1.5 \pm 0.3$ & 20 \\
O & $70 \pm 50$ & $7 \pm 4$ & $1.7 \pm 0.3$ & 3 \\
\hline
\end{tabular}

\subsection{Scattering Ångström exponent}

The Ångström exponent is a parameter which is directly related to the aerosol size distribution and can be used to analyze in a simple but compact way the relative proportion of fine and coarse particles in the size distribution. When the distribution consists mainly of fine particles, this parameter has values in the range of 1.5 to 2.0 , while it has values close to zero (even negative in some cases) when the distribution consists of particles of a larger radius (dust, hygroscopic or aggregated particles) (Seinfeld and Pandis, 1998).

Figure 4 shows the classification of the scattering Ångström exponent $\left(\alpha_{s}\right)$ with the air mass through a boxplot. Although one would expect the minimum values of $\alpha_{s}$ to be those of AF-type masses and their mixtures with TRtypes, as is the case in the extinction Ångström exponent in the atmospheric column for the same region (Estellés et al., 2007a), these correspond, on the contrary, to those of PO and AR-type masses, which are cleaner air masses but can carry a mixture of sea salts immersed in an air with high levels of humidity and mineral dust, causing a low value of the scattering Ångström exponent. The main reason for this is that the transportation of mineral dust generally occurs in the middle layers of the troposphere, so AF-type masses are not always detectable at the surface (Derimian et al., 2006; Elias et al., 2006; Pereira et al., 2011). The maximum $\alpha_{s}$ values are found in EU-type masses, which carry large amounts of polluting particles of anthropogenic origin (soot produced in the combustion of fossil fuels) which are located in the accumulation way of size distribution (particles with sizes between $0.1 \mu \mathrm{m}$ and $1 \mu \mathrm{m}$ ). O-type masses also have high values of $\alpha_{s}$, probably due to the existence of particles from pollution and continental coarse dust or sea salt in warm, humid environments of the Mediterranean Sea. These results for the maximum values of $\alpha_{s}$ coincide with those obtained by Estellés et al. (2007a) for the extinction Ångström exponent in the atmospheric column for the same region.

The scattering Ångström exponent values on the surface are slightly larger than the values of the extinction Ångström exponent in the atmospheric column obtained for the same region (Estellés et al., 2007a). These differences between the results obtained for the land surface and the atmospheric column have been also observed by other authors (Lyamani et al., 2010), and are mainly due to the different techniques used in obtaining the Ångström exponent: the values observed for the atmospheric column are obtained by averaging the light extinction throughout the atmospheric column, while the values of the TSI 3563 integrating nephelometer are obtained from light scattering measurements performed on the surface.

Table 1 shows a summary of the classification of the aerosol properties according to the type of air masses, basic and mixed of two components.

\section{Conclusions}

The influence of the trajectories of air masses has been analyzed in the in situ measurements of aerosol properties in Valencia for the March 2006 to December 2009 period. The scattering $\left(\sigma_{s p}\right)$ and backscattering $\left(\sigma_{b s p}\right)$ coefficients were measured with a TSI 3563 integrating nephelometer. The scattering Ångström exponent $\left(\alpha_{s}\right)$ was also determined from $\sigma_{s p}$ and $\sigma_{b s p}$ measurements.

By classifying the source regions of air masses by sectors, and with the help of a simple model that quantifies the relative influence of each sector on the final character of air masses reaching the measurement station, it has been possible to establish the dependence of these aerosol properties with the type of dominant air mass. It has been checked, therefore, that the measurements of the aerosol properties performed at ground level are parameters that are sensitive to the type of air mass.

Pure and mixed AF-type masses have maximum values of scattering and backscattering coefficients, and the values of the scattering Ångström exponent are higher than expected, given the presence of mineral dust in these kinds of air masses, which usually provide many larger size aerosols in the upper atmosphere.

Mixed and pure EU-type masses present high values of scattering and backscattering coefficients and maximum values of the scattering Ångström exponent, since they transport large numbers of polluting particles of anthropogenic origin.

Mixed and pure TR-type masses also present high values of scattering and backscattering coefficients, although the values of the scattering Ångström exponent are low, probably due to the presence of traces of mineral dust of desert origin plus the effect of relatively high temperatures and humidity that favor hygroscopic growth of sea salt and other aerosols resulting from gas - particle conversion. 
Mixed and pure AR and PO-type masses have the lowest values of scattering and backscattering coefficients, since they are cleaner air masses, as well as of the scattering Angström exponent, probably due to the presence of a mixture of marine salts immersed in an air with high humidity and mineral dust levels.

Finally, O-type masses have high values of scattering and backscattering coefficients, as well as scattering Ångström exponent, because they get trapped in the study area facilitating the accumulation of various anthropogenic pollutants, which in the Mediterranean basin are added to dust of possible peninsular or African origin.

Given that aerosol properties at a certain time over a region are the result of contributions from local sources and distant sources, the results obtained in this study can be considered valid for the entire Mediterranean coast of the Iberian Peninsula as well as for the entire southwest of Europe since the contribution of distant sources, which depends on the type of air mass, will be similar, although the contribution of local sources depends largely on the study region.

Acknowledgements. This study was financed by the Spanish Ministry of Science and Innovation (MICINN) through projects CGL2009-07790 and CGL2011-24290, and by the Generalitat Valenciana through project PROMETEO-2010-064. The collaboration of A.R. Esteve, S. Segura and V. Estellés was possible thanks to fellowships BES-2006-12521, BES-2010-031626 and JCI-200904455, respectively.

\section{References}

Anderson, T. L. and Ogren, J. A., 1998: Determining aerosol radiative properties using the TSI 3563 integrating nephelometer, Aerosol Sci Technol, 29, 57-69.

Anderson, T. L., Covert, D. S., Marshall, S. F., Laucks, M. L., Charlson, R. J., Waggoner, A. P., Ogren, J. A., Caldow, R., Holm, R. L., Quant, F. R., Sem, G. J., Wiedensohler, A., Ahlquist, N. C., and Bates, T. S., 1996: Performance characteristics of high sensitivity, three-wavelength, total scatter/backscatter nephelometer, J Atmos Ocean Technol, 13, 967-986.

Barry, R. G. and Chorley, R. J., 1998: Atmosphere, Weather and Climate, 7th ed. Routledge, Boca Raton, Florida, USA, 409 pp.

Birmili, W., Wiedensohler, A., Heintzenberg, J., and Lehman, K., 2001: Atmospheric particle number size distribution in central Europe: Statistical relations to air masses and meteorology, J Geophys Res, 106, 32 005-32 018, doi:10.1029/2000JD000 220.

Charlson, R. J. and Heintzenberg, J., 1995: Aerosol Forcing of Climate, John Wiley, Hoboken, New Jersey, USA, 416 pp.

Derimian, Y., Karnieli, A., Kaufmann, Y. J., Andreae, M. O., Andreae, T. W., Dubovik, O., Maenhaut, W., Koren, I., and Holben, B. N., 2006: Dust and pollution aerosols over the Negev desert, Israel: properties, transport and radiative effect, J Geophys Res, 111, D05 205, doi:10.1029/2005JD006 549.

Dorling, S. R., Davies, T. D., and Pierce, C. E., 1992: Cluster analysis: A technique for estimating the synoptic meteorological controls on air and precipitation chemistry-Method and applications, Atmos Environ, 26, 2575-2581.

Draxler, R. R. and Rolph, G. D., 2003: HYSPLIT (HYbrid SingleParticle Lagrangian Integrated Trajectory) Model access via
NOAA ARL READY Website (http://www.arl.noaa.gov/ready/ hysplit4.html), NOAA Air Resources Laboratory, Silver Spring, MD.

Elias, T., Silva, A. M., Belo, N., Pereira, S., Formenti, P., Helas, G., and Wagner, F., 2006: Aerosol extinction in a remote continental region of the Iberian Peninsula during summer, J Geophys Res, 111, D14 204, doi:10.1029/2005JD006 610.

Estellés, V., 2006: Caracterización de los aerosoles atmosféricos en Valencia mediante fotometría solar, Tesis Doctoral, Universitat de València, Valencia.

Estellés, V., Martínez-Lozano, J. A., and Utrillas, M. P., 2007a: Influence of air mass history on the columnar aerosol properties at Valencia, Spain, J Geophys Res, 112, D15211, doi:10.1029/2007JD008 593.

Estellés, V., Martínez-Lozano, J. A., Utrillas, M. P., and Campanelli, M., 2007b: Columnar aerosol properties in Valencia (Spain) by ground-based Sun photometry, J Geophys Res, 112, D11 201, doi:10.1029/2006JD008 167.

Esteve, A. R., Estellés, V., Utrillas, M. P., and Martínez-Lozano, J. A., 2012: In-situ integrating nephelometer measurements of the scattering properties of atmospheric aerosols at an urban coastal site in western Mediterranean, Atmos Environ, 47, 4350, doi:10.1016/j.atmosenv.2011.11.043.

Gerasopoulos, E., Andreae, M. O., Zeferos, C. S., Andreae, T. W., Balis, D., Formenti, P., Merlet, P., Amiridis, V., and Papastefanou, C., 2003: Climatological aspects of aerosol optical properties in Northern Greece, Atmos Chem Phys, 3, 2025-2041, doi:10.5194/acp-3-2025-2003.

Grousset, F. E., Ginoux, P., Bory, A., and Biscaye, P. E., 2003: Case study of a Chinese dust plume reaching the French Alps, Geophys Res Lett, 30, 1277, doi:10.1029/2002GL016 833.

He, Z., Kim, Y. J., Ogunjobi, K. O., and Hong, C. S., 2003: Characteristics of PM2.5 species and long-range transport of air masses at Taean background station, South Korea, Atmos Environ, 37, 219-230.

Heintzenberg, J. and Charlson, R. J., 1996: Design and applications of the integrating nephelometer: A review, J Atmos Ocean Technol, 13, 987-1000.

Lyamani, H., Olmo, F. J., and Alados-Arboledas, L., 2010: Physical and optical properties of aerosol over an urban location in Spain: seasonal and diurnal variability, Atmos Chem Phys, 10, 239-254, doi:10.5194/acp-10-239-2010.

Mattis, I., Jaenisch, V., Müller, D., Franke, K., and Ansmann, A., 2000: Classification of particle extinction profiles derived within the framework of the German lidar network by the use of cluster analysis of backtrajectories, en Advances in laser remote sensing, Ecole Polytechnique, Palaiseau, France.

Millán, M. M., Salvador, R., Mantilla, E., and Artiñano, B., 1996: Meteorology and photochemical air pollution in southern Europe: experimental results from EC research projects, Atmos Environ, 30, 1909-1924.

Millán, M. M., Salvador, R., Mantilla, E., and Kallos, G., 1997: Photooxidant dynamics in the Mediterranean basin in summer: Results from European research projects, J Geophys Res, 102, 8811-8823.

Millán, M. M., Mantilla, E., Salvador, R., Carratalá, A., Sanz, M. J., Alonso, L., Gangoiti, G., and Navazo, M., 2000: Ozone Cycles in the Western Mediterranean Basin: Interpretation of Monitoring Data in Complex Coastal Terrain, J Appl Meteorol, 39, 487-508.

Niemi, J. V., Tervahattu, H., Vehkamäki, H., Kulmala, M., Koskentalo, T., Sillanpää, M., and Rantamäki, M., 2004: Characteriza- 
tion and source identification of a fine particle episode in Finland, Atmos Environ, 38, 5003-5012.

Ogren, J. A., 1995: A systematic approach to in situ observations of aerosol properties, Aerosol Forcing of Climate, John Wiley, New York, USA.

Pereira, S., Wagner, F., and Silva, A. M., 2011: Seven years of measurements of aerosol scattering properties, near the surface, in the southwestern Iberia Peninsula, Atmos Chem Phys, 11, 1729, doi:10.5194/acp-11-17-2011.

Rozwadowska, A., Zieliński, T., Petelski, T., and Sobolewski, P., 2010: Cluster analysis of the impact of air back-trajectories on aerosol optical properties at Hornsund, Spitsbergen, Atmos Chem Phys, 10, 877-893, doi:10.5194/acp-10-877-2010.

Seinfeld, J. H. and Pandis, S. N., 1998: Atmospheric Chemistry and Physics, from Air Pollution to Climate Change, John Wiley, New York.

Slater, J. F. and Dibb, J. E., 2004: Relationships between surface and column aerosol radiative properties and air mass transport at a rural New England site, J Geophys Res, 109, D01 303, doi:10.1029/2003JD003 406.

Targino, A. C., Noone, K. J., and Öström, E., 2005: Airborne in situ characterization of dry aerosol optical properties in multisource influenced marine region, Tellus B, 57, 247-260.

Toledano, C., Cachorro, V. E., de Frutos, A. M., Torres, B., Berjón, A., Sorribas, M., and Stone, R. S., 2009: Airmass classification and analysis of aerosol types at El Arenosillo (Spain), J Appl Meteorol Climatol, 48, 962-981, doi:10.1175/2008JAMC2006.1. 